\title{
Research
}

\section{Feasibility and indicative results from a 12-month low-energy liquid diet treatment and maintenance programme for severe obesity}

\begin{abstract}
Background

There is no established primary care solution for the rapidly increasing numbers of severely obese people with body mass index (BMI) $>40 \mathrm{~kg} / \mathrm{m}^{2}$.

Aim

This programme aimed to generate weight losses of $\geq 15 \mathrm{~kg}$ at 12 months, within routine primary care.

\section{Design and setting \\ Feasibility study in primary care.}

\section{Method}

Patients with a $\mathrm{BMI} \geq 40 \mathrm{~kg} / \mathrm{m}^{2}$ commenced a micronutrient-replete 810-833 kcal/day lowenergy liquid diet (LELD), delivered in primary care, for a planned 12 weeks or $20 \mathrm{~kg}$ weight loss (whichever was the sooner), with structured food reintroduction and then weight-loss maintenance, with optional orlistat to 12 months.

\section{Results}

Of 91 patients (74 females) entering the programme (baseline: weight $131 \mathrm{~kg}$, BMI $48 \mathrm{~kg}$ / $\mathrm{m}^{2}$, age 46 years), 58/91(64\%) completed the

LELD stage, with a mean duration of 14.4 weeks (standard deviation [SD] $=6.0$ weeks), and a mean weight loss of $16.9 \mathrm{~kg}$ (SD $=6.0 \mathrm{~kg}$ ). Four patients commenced weight-loss maintenance omitting the food-reintroduction stage. Of the remaining 54,37(68\%) started and completed food reintroduction over a mean duration of 9.3 weeks (SD = 5.7 weeks), with a further mean weight loss of $2.1 \mathrm{~kg}$ (SD = $3.7 \mathrm{~kg}$ ), before starting a long-term low-fat-diet weight-loss maintenance plan. A total of $44 / 91$ (48\%)

\section{INTRODUCTION}

Severe obesity is increasing rapidly, with no established community-based solutions. A little higher than in the UK, the prevalence of body mass index (BMI) above $35 \mathrm{~kg} / \mathrm{m}^{2}$ in Scotland is now $6 \%$ in men and $11 \%$ in women, of whom $20 \%$ and $11 \%$ respectively (overall 14\%) have diagnosed diabetes. ${ }^{1,2}$ By the age of $55-64$ years, $5 \%$ of women and $3 \%$ of men exceed a BMl of $40 \mathrm{~kg} /$ $\mathrm{m}^{2}$, risking multiple symptoms and major comorbidities. ${ }^{3}$

Previous weight-management guidelines targeted $\mathrm{BMI} \geq 30 \mathrm{~kg} / \mathrm{m}^{2}$, with a $5-10 \%$ weight-loss and maintenance goal, derived from the Scottish Intercollegiate Guidelines Network (SIGN) 1996 target of $5-10 \mathrm{~kg}$ weight loss. ${ }^{4}$ While a weight loss of 5-10 kg can prevent progression from impaired glucose tolerance to diabetes, and improves all metabolic markers, ${ }^{5,6}$ it does not reverse established diagnoses of diabetes, or its complications. The 2010 SIGN obesity guideline set a new target of $\geq 15 \%$ loss for those with $\mathrm{BMI} \geq 35 \mathrm{~kg} / \mathrm{m}^{2}$ and with serious medical complications like type 2 diabetes. ${ }^{7}$ A weight loss of $\geq 15 \mathrm{~kg}$ (close to $15 \%$ given a baseline weight of 104-106 kgl is needed to normalise both glucose and
\end{abstract} received orlistat at some stage. At 12 months, weight was recorded for 68/91 (75\%) patients, with a mean loss of $12.4 \mathrm{~kg}$ (SD $=11.4 \mathrm{~kg})$. Of these, 30 (33\% of all 91 patients starting the programmel had a documented maintained weight loss of $\geq 15 \mathrm{~kg}$ at 12 months, six (7\%) had a $10-15 \mathrm{~kg}$ loss, and 11 (12\%) had a $5-10 \mathrm{~kg}$ loss. The indicative cost of providing this entire programme for wider implementation would be $€ 861$ per patient entered, or $€ 2611$ per documented $15 \mathrm{~kg}$ loss achieved.

\section{Conclusion}

A care package within routine primary care for severe obesity, including LELD, food reintroduction, and weight-loss maintenance was well accepted and achieved a 12-monthmaintained weight loss of $\geq 15 \mathrm{~kg}$ for one-third of all patients entering the programme.

\section{Keywords}

healthcare economics and organizations; morbid

obesity; orlistat; primary health care.
M Lean, MA, MBBChir, MD, professor of human nutrition and honorary consultant physician Human Nutrition School of Medicine:

P McLoone, BSc, statistician; B Sloan, BSc, data development manager; D Morrison, MRCPI, MPH, FFPH, MD, reader in public health, Public Health; M Mackenzie, BA Hons, MPH, PhD, senior lecturer, Urban Studies; E Grieve, BA, MPH, research assistant, HEHTA, Institute of Health and Well Being. University of Glasgow, Glasgow. N Brosnahan, BSc, PGDipDiet, RD, business executive; L McCombie, BSc, PGDipDiet, RD, chief operating officer; A Bell Higgs, BSc, RD Counterweight Specialist; H Ross, BSc, PGDipDiet $R D$, chief executive officer, Counterweight Ltd, Edinburgh. N Finer, BSc, MRCP, consultant endocrinologist/honorary professor of medicine UCL Institute of Cardiovascular Science, London J Reckless, DSc, MD, FRCP, honorary reader in insulin, 8,9 and virtually all patients who lost $\geq 15 \%$ or $\geq 15 \mathrm{~kg}$ in a controlled trial of bariatric surgery returned to normal glucose tolerance, ${ }^{10}$ supporting extensive observational evidence. ${ }^{11}$ Extrapolation of published audit data suggests that intentional weight loss of $15 \mathrm{~kg}$ might even normalise the reduced life expectancy of overweight patients with type 2 diabetes. ${ }^{12}$

A target of sustained weight loss of more than $15 \mathrm{~kg}$ is essentially aspirational in routine clinical practice. ${ }^{13}$ Only $1.7 \%$ maintained a weight loss of $\geq 15 \mathrm{~kg}$ in the original Counterweight Programme, which targeted $5-10 \%$ loss. With the addition of anti-obesity drugs, about $5-10 \%$, and maybe $20 \%$ with liraglutide $3 \mathrm{mg} /$ day, lose $\geq 15 \mathrm{~kg}^{14-17}$ To lose $15 \mathrm{~kg}$ of adipose tissue, at $7000 \mathrm{kcal} / \mathrm{kg}$, ${ }^{18}$ demands a negative energy balance of about $100000 \mathrm{kcal}$, assuming $2800 \mathrm{kcal} /$ day energy expenditure of obese patients. This is achievable in about 7 weeks with an $800 \mathrm{kcal} /$ day diet. However, adherence is often incomplete, with little difference in 12-month weight change between lowenergy liquid diets (LELDs, $\geq 800-1200 \mathrm{kcal} /$ dayl or very low-energy diets (VLEDs, 400-800 kcal/day]. ${ }^{19-21}$ With improved

medicine/consultant endocrinologist, Wolfson Centre, Royal United Hospital, Bath and University of Bath, Bath. D Haslam, MBBS, DGM, GP, GPwSI obesity, Watton Place Clinic and bariatric physician, Luton and Dunstable Hospital, Luton.

\section{Address for correspondence}

Michael Lean, School of Medicine, Human Nutrition, Walton Building, Royal Infirmary, Glasgow, G4 OSF.

E-mail: Mike.Leandglasgow.ac.uk

Submitted: 1 June 2012; Editor's response: 13 July 2012; final acceptance: 29 August 2012. (CBritish Journal of General Practice

This is the full-length article (published online 28 Jan 2013) of an abridged version published in print. Cite this article as: Br J Gen Pract 2013; DOI: 10.3399/bjgp13X663073 


\section{How this fits in \\ It is a popular belief that liquid-formula diets are ineffective beyond an initial rapid weight loss, and that most people fail to maintain lower weight and will experience weight regain to above the baseline value. They are not routinely available or accepted in primary care. No effective approach other than bariatric surgery is offered to morbidly obese patients, and bariatric procedures have limited access in the current UK NHS. This study has shown that a low-energy liquid diet, with an effective 12-month weight-maintenance programme (including optional orlistat), is very acceptable to clinicians and to morbidly obese patients within routine primary care. A 12-month maintained weight loss of $\geq 15 \mathrm{~kg}$ lenough to reverse type 2 diabetes) was achieved by 31 of the 91 severely obese patients who entered the study, at an anticipated cost of $€ 861$ per patient if widely implemented.}

formulation and weight-regain-prevention programmes, safety concerns about VLEDs have declined, ${ }^{22,23}$ but they are seldom recommended in weight-management guidelines, because of the expected weight

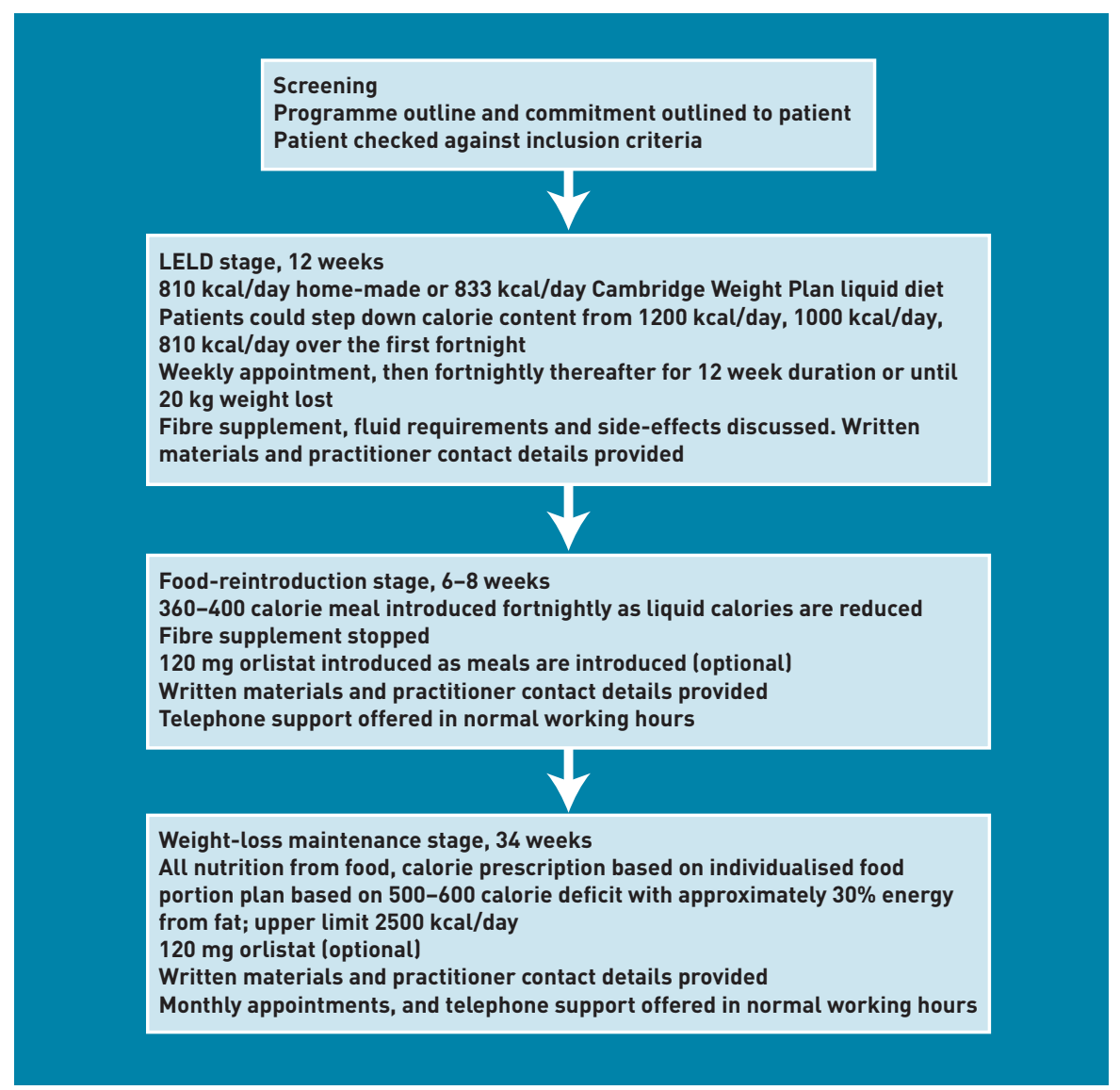

regain. However, meta-analysis showed a mean weight below baseline after 2 years, ${ }^{15}$ and substantial numbers can maintain $\geq 15$ kg loss 18-36 months after a VLED or LELD, using structured food-reintroduction programmes and anti-obesity drugs. 19,24-26

The present feasibility study investigated the acceptability, adherence, and costs of a LELD intervention, aiming to achieve $\geq 15 \mathrm{~kg}$ weight loss at 12 months, among severely obese patients attending routine primary care.

\section{METHOD}

The feasibility study was conducted in practices already delivering Counterweight, ${ }^{27}$ predominately in rural or small-town settings (16/25 providing $67 \%$ of study patients), nine of which were urban, in 7/13 Counterweight-trained health boards (Figure 1). Socioeconomic profiles of practice localities varied around the all-Scotland average: $96 \%$ of patients attended practices between the 20th and 80th percentiles of deprivation scores. ${ }^{28}$

Six practice nurses and eight dietitians, competent in Counterweight Programme delivery, ${ }^{29}$ attended 8 hours of training, delivered by Counterweight specialist dietitians and physicians with expertise in LELD, addressing the study protocol, programme delivery, and evaluation. Comprehensive educational resources for practitioners and patients were supplied, and Counterweight specialists provided on-the-job mentoring, and telephone/ email support, for programme-delivery staff. Expenses incurred for training were reimbursed, but the LELD programme was then delivered within routine practice, without additional incentives.

\section{Participant numbers and representation}

This feasibility study was not subject to power calculations. It aimed to recruit 60 patients, proposed by GPs, practice nurses, or local dietitians, over 6 months, anticipating $20-30 \%$ drop-outs, to leave 40 completing patients. Males and females, aged $20-60$ years with $\mathrm{BMI} \geq 40 \mathrm{~kg} / \mathrm{m}^{2}$, were included if they were ready to undertake the programme. Exclusions were: pregnancy or lactation, diabetes and taking insulin or sulphonylureas, myocardial infarction within 6 months, cancers, chronic pancreatitis, alcohol dependence, psychiatric illness, and learning disability.

\section{LELD stage (12 weeks or $20 \mathrm{~kg}$ weight loss, whichever was sooner)}

Following screening, to check inclusion criteria, readiness, and ability to commit to 
Table 1. Baseline characteristics of participants

\begin{tabular}{lccc} 
& Males & Females & All \\
\hline$n(\%)$ & $17(18.7)$ & $74(81.3)$ & $91(100.0)$ \\
\hline Age, years (SD) & $47.4(11.4)$ & $45.4(10.6)$ & $45.7(10.7)$ \\
\hline Height, cm (SD) & $175.8(8.4)$ & $162.6(7.0)$ & $165.0(8.9)$ \\
\hline Weight, kg (SD) & $152.9(31.9)$ & $126.1(20.7)$ & $131.1(25.2)$ \\
\hline $\mathrm{BMl}, \mathrm{kg} / \mathrm{m}^{2}$ (SD) & $49.6(10.3)$ & $47.6(6.8)$ & $48.0(7.6)$ \\
\hline
\end{tabular}

$B M I=$ body mass index. $S D=$ standard deviation .

Table 2. Weight change from baseline during the LELD, during foodreintroduction, and over the entire 12 months of study

\begin{tabular}{|c|c|c|c|}
\hline Weight-change categories & All, \% $(n)$ & $\begin{array}{l}\text { Patients who } \\
\text { continued to food } \\
\text { reintroduction/weight } \\
\text { maintenance, } \%(n)\end{array}$ & $\begin{array}{l}\text { Patients who withdrew } \\
\text { before food } \\
\text { reintroduction, \% (n) }\end{array}$ \\
\hline \multicolumn{4}{|l|}{ During LELD, kg } \\
\hline$\geq 5$ to $<10$ & $1(1)$ & $0(0)$ & $3(1)$ \\
\hline$>0$ to $\leq 5$ & $1(1)$ & $0(0)$ & $3(1)$ \\
\hline$>-5$ to $\leq 0$ & $19(17)$ & 5 (3) & $42(14)$ \\
\hline$>-10$ to $\leq-5$ & $18(16)$ & $10(6)$ & $30(10)$ \\
\hline$>-15$ to $\leq-10$ & $15(14)$ & $17(10)$ & $12(4)$ \\
\hline$>-20$ to $\leq-15$ & $21(19)$ & $29(17)$ & $6(2)$ \\
\hline$>-25$ to $\leq-20$ & $22(20)$ & $34(20)$ & $0(0)$ \\
\hline$>-30$ to $\leq-25$ & $1(1)$ & $2(1)$ & $0(0)$ \\
\hline$\leq-30$ & $2(2)$ & $2(1)$ & $3(1)$ \\
\hline Patients, \% (n) & $100(91)$ & $64(58)$ & 36 (33) \\
\hline Mean weight change, kg (SD) & $-13.1(8.0)$ & $-16.9(6.0)$ & $-6.6(6.3)$ \\
\hline Mean \% weight change (SD) & $-10.0(6.0)$ & $-12.6(4.5)$ & $-5.1(5.3)$ \\
\hline \multicolumn{4}{|l|}{ During food reintroduction, $\mathrm{kg}$} \\
\hline$\geq 5$ to $<10$ & $2(1)$ & $2(1)$ & $0(0)$ \\
\hline$>0$ to $<5$ & $24(13)$ & 25 (12) & $17(1)$ \\
\hline$>-5$ to $\leq 0$ & $46(25)$ & $46(22)$ & $50(3)$ \\
\hline$>-10$ to $\leq-5$ & $24(13)$ & $25(12)$ & $17(1)$ \\
\hline$>-15$ to $\leq-10$ & $2(1)$ & $2(1)$ & $0(0)$ \\
\hline Not known & $2(1)$ & $0(0)$ & $17(1)$ \\
\hline Patients, \% $(n)$ & $100(54)$ & 89 (48) & $100(6)$ \\
\hline Mean weight change, kg (SD) & $-2.0(3.7)$ & $-2.1(3.7)$ & $-1.3(3.1)$ \\
\hline \multirow[t]{2}{*}{ Mean \% weight change (SD) } & $-1.6(3.0)$ & $-1.6(3.1)$ & $-0.8(2.2)$ \\
\hline & & $\begin{array}{c}\text { Patients who continued } \\
\text { to weight } \\
\text { maintenance, } \%(n)\end{array}$ & $\begin{array}{l}\text { Patients who withdrew } \\
\text { during food } \\
\text { reintroduction, \% (n) }\end{array}$ \\
\hline \multicolumn{4}{|c|}{ Over the entire 12 months of study, $\mathrm{kg}$} \\
\hline$\geq 5$ to $<10$ & $2(2)$ & $2(1)$ & $3(1)$ \\
\hline$>0$ to $<5$ & $8(7)$ & 6 (3) & $10(4)$ \\
\hline$>-5$ to $\leq 0$ & $13(12)$ & $15(8)$ & $10(4)$ \\
\hline$>-10$ to $\leq-5$ & $12(11)$ & $12(6)$ & $13(5)$ \\
\hline$>-15$ to $\leq-10$ & $7(6)$ & $8(4)$ & $5(2)$ \\
\hline$>-20$ to $\leq-15$ & $16(15)$ & 25 (13) & $5(2)$ \\
\hline$>-25$ to $\leq-20$ & $7(6)$ & $12(6)$ & $0(0)$ \\
\hline$>-30$ to $\leq-25$ & $4(4)$ & $8(4)$ & $0(0)$ \\
\hline$\leq-30$ & $5(5)$ & $8(4)$ & $3(1)$ \\
\hline Not known & 25 (23) & 6 (3) & $51(20)$ \\
\hline Patients, \% (n) & $100(91)$ & $57(52)$ & 43 (39) \\
\hline Mean weight change, kg (SD) & $-12.4(11.4)$ & $-14.7(10.8)$ & $-6.7(11.1)$ \\
\hline Mean \% weight change (SD) & $-9.1(8.2)$ & $-10.9(8.0)$ & $-4.6(6.9)$ \\
\hline
\end{tabular}

the 12-month LELD programme, patients were asked to follow either a 'home-made' milk- and fruit-juice-based diet $(811 \mathrm{kcal} /$ day, $64 \mathrm{~g}$ protein, $132 \mathrm{~g}$ carbohydrate, $6 \mathrm{~g}$ fat) with a multivitamin/mineral supplement (Forceval ${ }^{\circledR}[$ Alliance],,30 or a micronutrientreplete commercial LELD $\quad 832 \mathrm{kcal} /$ day, $87 \mathrm{~g}$ protein, $120 \mathrm{~g}$ carbohydrate, $12 \mathrm{~g}$ fat) (Cambridge Weight Plan, UK). 'Mixing and matching' these diets was permitted, with optional LELD step-down from $1200 \mathrm{kcal} /$ day to $810 / 832 \mathrm{kcal} /$ day over 2 weeks, to optimise compliance. After 1 week, and fortnightly thereafter, a structured programme of topics was addressed, including weight-loss targets and expectations, relapse prevention, selfmonitoring, and social support, with written support materials, including detecting and managing problems. A fibre supplement (Fyboge ${ }^{\circledR} \quad$ [ispaghula husk, Reckitt Benckiser]) was prescribed as required, and advice to drink $2.25 \mathrm{~V} /$ day plus LELD soups/ shakes. Telephone support was offered.

\section{Food reintroduction (6-8 weeks)}

Initially, one 360-400 kcal meal, based on the 'eatwell plate', ${ }^{31}$ plus two fruit servings/ day was introduced, the LELD was reduced, and orlistat offered $(120 \mathrm{mg} / \mathrm{meal}$ ). Allowing some individual flexibility, further meals were introduced fortnightly until LELD was replaced with three meals per day. Patients attended fortnightly, receiving printed support materials on weight-loss maintenance, nutrition, physical activity, goal setting, energy requirements, portion control, and orlistat, with telephone support if necessary.

\section{Weight-loss maintenance luntil} 12 months)

Patients progressed gradually from their final food-reintroduction prescription (1400 kcal/day) to an individual prescribed eating plan', based on food portions containing 30\% energy from fat, with a $500-$ $600 \mathrm{kcal} /$ day deficit below the requirement predicted from age, weight, and sex, ${ }^{32}$ and an upper limit of $2500 \mathrm{kcal} / \mathrm{day}{ }^{33}$ Thirty minutes per day of moderate physical activity was encouraged, ${ }^{34}$ with sustainable individually-tailored goal setting to increase activity. ${ }^{33}$ Patients attended monthly to consolidate strategies introduced during the LELD and food reintroduction, with early discussions on relapse prevention, goal setting, portion control, and physical activity.

\section{Outcome evaluations for analysis}

Qualitative and quantitative information were recorded on: patient and practitioner 


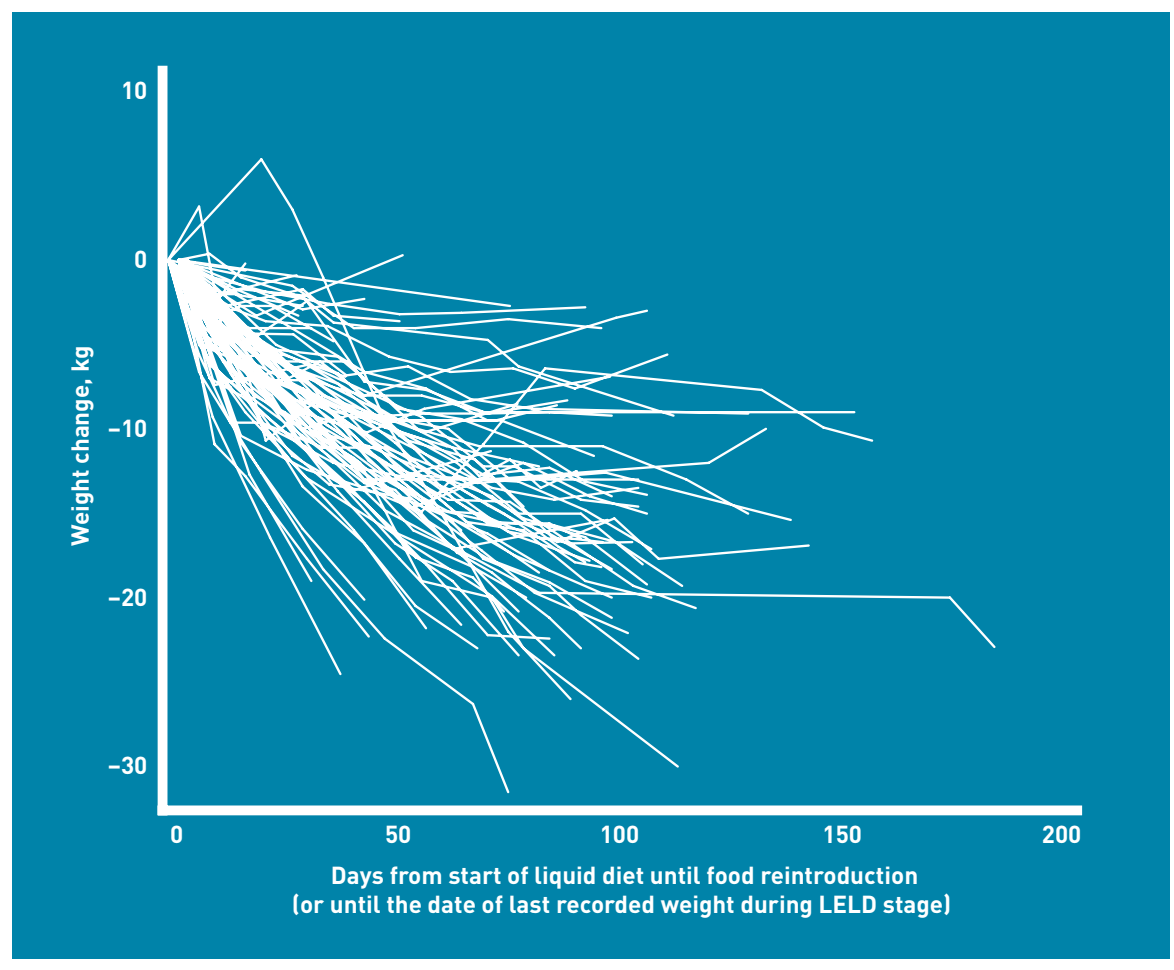

Figure 2. Weight-change trajectories from the start of the liquid diet.

weight maintenance, attendance throughout weights) recorded a documented weight loss of $\geq 15 \mathrm{~kg}$ at 12 months, six lost $10-15 \mathrm{~kg}, 11$ lost $5-10 \mathrm{~kg}$, and $21131 \%$ of those with a 12-month weight) failed to reduce their weight by more than $5 \mathrm{~kg}$. Weight loss of $\geq 15 \%$ was documented for 17 (19\% of those entering, $25 \%$ of those with a 12-month weight). There were $29 / 58$ who achieved $\geq 15 \mathrm{~kg}$ loss at 12 months within a measurement window of \pm 60 days and $27 / 45$ within a window of \pm 30 -days

\section{LELD stage}

Ninety-one patients entered the study $(74$ females), with a mean BMI of $48 \mathrm{~kg} / \mathrm{m}^{2}$ (Table 1). Fifty-eight completed the LELD (Table 2, Figure 2). At baseline, 82 patients chose the commercial LELD, two chose the homemade LELD, and six chose to use both (one not recorded). All patients used the commercial product at some point, 81 solely.

To optimise patient retention, some protocol variations were accepted, and their reasons contributed to learning about the feasibility. Three patients stopped the LELD at 8.2 weeks (SD $=3.5$ weeks), starting food reintroduction before 12 weeks without losing $20 \mathrm{~kg}$, with a mean weight loss of $16.5 \mathrm{~kg}$ (SD $=2.2 \mathrm{~kg} ; 11.5 \%$ change, $\mathrm{SD}=2.7 \%$ ). Eleven lost $\geq 20 \mathrm{~kg}$ with the LELD and started food reintroduction before 12 weeks, according to protocol, with a weight loss of $22.7 \mathrm{~kg}$ (SD $=3.3 \mathrm{~kg}$; $15.7 \%$ change, SD $=2.3 \%$ ) over 9.1 weeks $(S D=2.3$ weeks $)$. Thirty-six continued the LELD beyond 12 weeks before food reintroduction, with a weight loss of $15.6 \mathrm{~kg}$ $(S D=5.7 \mathrm{~kg} ; 12.2 \%$ change, $S D=4.8 \%)$ over 15.1 weeks (SD $=2.3$ weeks). Four remained on the LELD beyond 12 weeks, commencing weight-loss maintenance directly (omitting food reintroduction), with weight loss of $11.3 \mathrm{~kg}$ (SD = $7.8 \mathrm{~kg}$; $8.4 \%$ change, $\mathrm{SD}=5.2 \%$ ), after 29.6 weeks (SD $=11.6$ weeks $)$. Thirty-three patients withdrew from the study during the LELD, after 6.8 weeks (SD $=5.4$ weeks), with a weight loss of $6.2 \mathrm{~kg}$ (SD $=6.6 \mathrm{~kg} ; 5.1 \%$ change, SD $=5.2 \%$ ).

The mean weight change was $16.9 \mathrm{~kg}$ $(S D=6.0 \mathrm{~kg} ; 12.6 \%$ change, $S D=4.5 \%$; $n=58$ ), after 14.4 weeks (SD $=6.0$ weeks) on the LELD. Forty-two $146 \%$ of enrolled patients, $69 \%$ of completers) lost $\geq 15 \mathrm{~kg}$ during the LELD, and 19 lost $\geq 15 \%$ (21\% of enrolled patients, $33 \%$ of completers).

\section{Food-reintroduction stage}

Of 54 patients entering this stage, three returned to the LELD and three dropped out. The mean weight change during food
Thirty patients $133 \%$ of 91 entering the programme, $44 \%$ of those with 12 -month

\section{RESULTS} weight loss was $12.4 \mathrm{~kg}$ (standard deviation $[\mathrm{SD}]=11.4 \mathrm{~kg} ; 9.1 \%$ loss, SD = $8.2 \% ; n=68$ ). programme stages, weight changes lusing at the nearest to 365 days from baseline, time, and resources used. Costs were computed from standard tables. follow-up were identified opportunistically professionals outwith the study. Analyses experience of LELD and weic daily life, and future expectations for weight maintenance. 


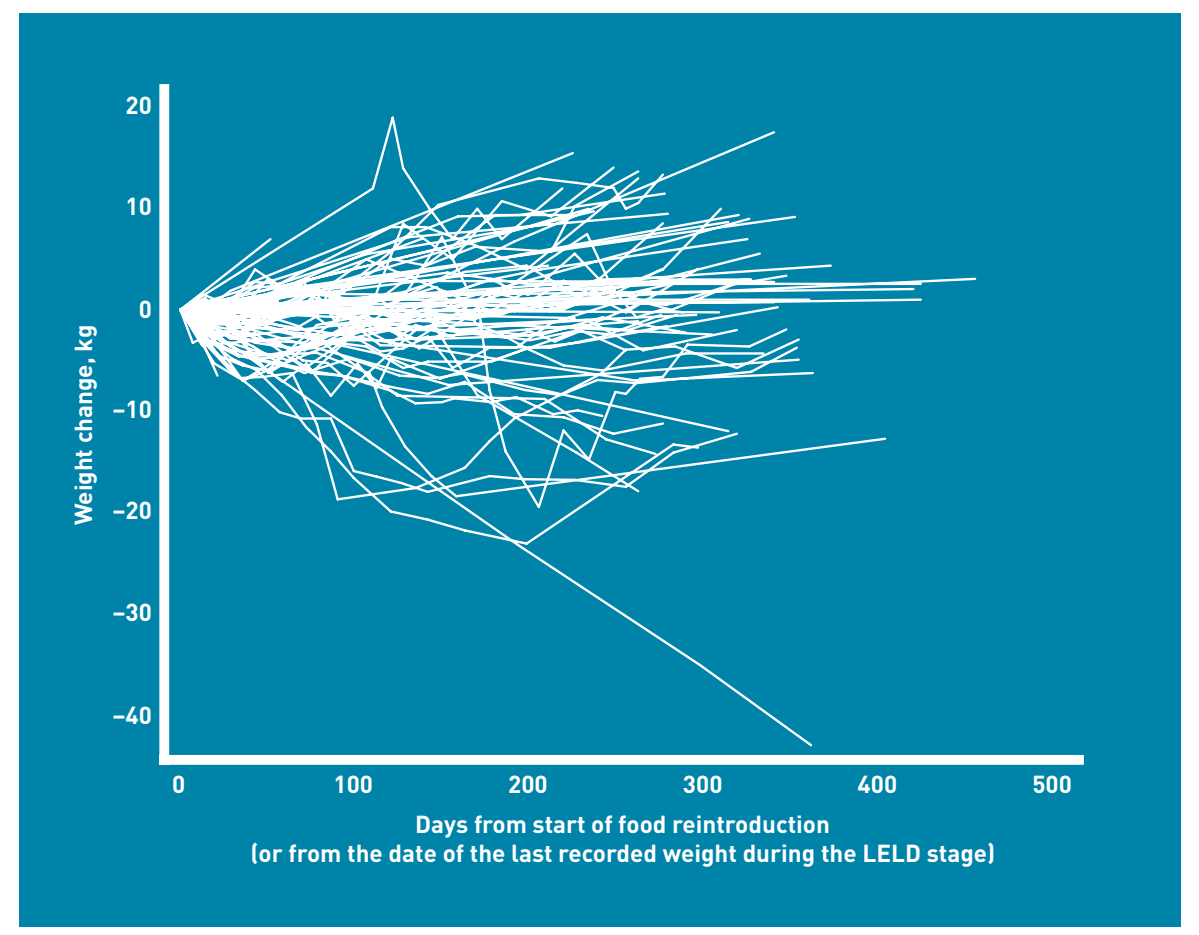

Figure 3. Weight-change trajectories from the start of food reintroduction.

Figure 4. Weight-change trajectories by duration in the programme. White lines indicate LELD weight loss.

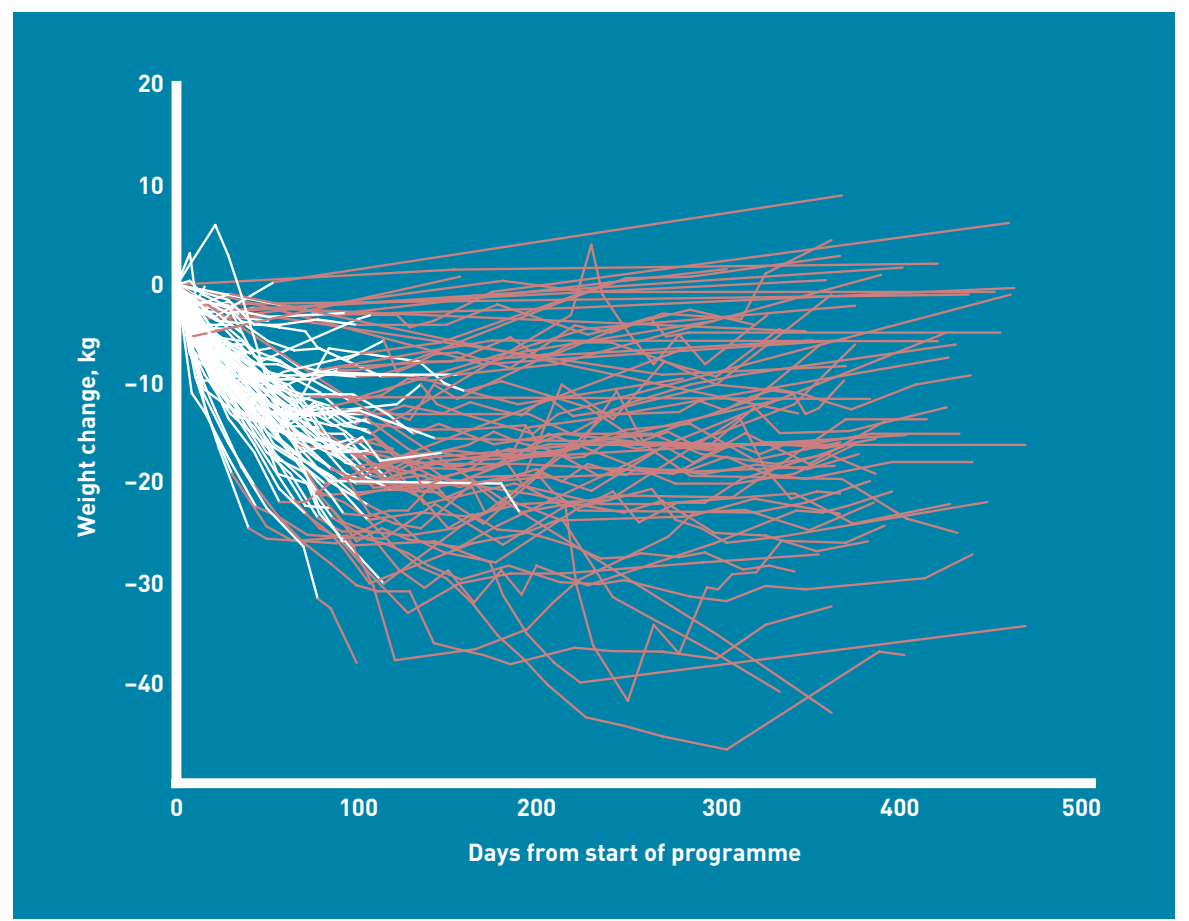

Weight-loss maintenance stage

Fifty-two patients commenced maintenance (48 after food reintroduction, four direct from the LELD) (Figure 3): 17 (33\%) reverted to LELD and/or food reintroduction for short periods (Figure 4).

Most patients $(49,94 \%)$ commencing weight-loss maintenance provided 12-month weights. The mean weight change from baseline to 12 months was $-14.7 \mathrm{~kg}$ (SD $=10.8 \mathrm{~kg}$, representing a regain of $3.6 \mathrm{~kg}(S D=6.7 \mathrm{~kg} ; 3.2 \%$ gain, $\mathrm{SD}=5.9 \%$ ) over 29 weeks (SD $=9$ weeks) during weight-loss maintenance. A total weight loss of $\geq 15 \mathrm{~kg}$ was recorded for 27 patients $(52 \%$ of patients who entered weight-loss maintenance, $55 \%$ of those who also provided 12-month weights). A weight loss of $\geq 15 \%$ was recorded for 15 $129 \%$ of those who entered weight-loss maintenance, $31 \%$ of those who also provided 12-month weights).

Twelve-month weights were also obtained for 19 (49\%) of 39 patients who had withdrawn before weight-loss maintenance. They had lost $6.7 \mathrm{~kg}$ ISD $=11.1 \mathrm{~kg} ; 4.6 \%$, $\mathrm{SD}=6.9 \%$ ) from baseline, which was $0.5 \mathrm{~kg}$ $(\mathrm{SD}=11.6 \mathrm{~kg} ; 0.4 \%, \mathrm{SD}=6.9 \%)$ below their last recorded weight, over 39 weeks (SD $=10$ weeks). Three of these 39 'dropouts' had lost $\geq 15 \mathrm{~kg}$, and two had lost $\geq 15 \%$ (Figure 4).

\section{Orlistat use}

Only 29\% (16/54) of patients accepted orlistat at the start of food reintroduction, but it was prescribed at some point to $44 / 91$ patients ( $82 \%$ of those who entered weight-loss maintenancel for 26 weeks (SD $=15$ weeks). The mean weight change at 12 months among those who had used orlistat at some point was $-15.5 \mathrm{~kg}$ $(\mathrm{SD}=11.1 \mathrm{~kg} ; 11.3 \%, \mathrm{SD}=8.3 \% ; n=38)$, compared to $-13.8 \mathrm{~kg}$ (SD $=8.4 \mathrm{~kg} ; 11.0 \%$, $\mathrm{SD}=6.9 \% ; n=8$ ) for those who did not. For patients receiving orlistat at 12 months ( $n=18$ ), the weight change was $-20.1 \mathrm{~kg}$ (SD $=8.0 \mathrm{~kg} ;-14.9 \%, \mathrm{SD}=6.0 \%$ ), compared to $-14.1 \mathrm{~kg}$ (SD = $11.4 \mathrm{~kg} ;-10.5 \%, \mathrm{SD}=8.2 \%$ ) for those not taking orlistat $(n=22)$.

\section{Practice nurses and dietitians for} programme delivery

Four nurses and nine dietitians delivered the programme, to 38 (mean baseline weight $124.0 \mathrm{~kg}, \quad S D=18.5 \mathrm{kgl}$ and 53 Imean baseline weight $136.2 \mathrm{~kg}$, $\mathrm{SD}=28.2 \mathrm{~kg}$ l patients respectively. Nurses spent less time per appointment (17.0 minutes, $\mathrm{SD}=5.7$ minutes), than dietitians (24.0 minutes, SD = 9.6 minutes; $P<0.001)$. Withdrawals during LELD were 


\section{Table 3. Indicative costs of providing service per 1000 patients, based on the actual number of visits and resource-utilisation data collected on 91 patients entered into the feasibility study}

\begin{tabular}{|c|c|c|c|}
\hline Item & $\begin{array}{l}\text { Units per } \\
1000 \text { patients }\end{array}$ & Units, hours & Cost per unit, $€$ \\
\hline GP time, minutes & 6000 & & 3.1035 \\
\hline \multicolumn{4}{|l|}{ Appointments year 1} \\
\hline Practice nurse number of visits, LELD & 7802 & 0.35 & $51.00^{35}$ \\
\hline Practice nurse number of visits, post-LELD & 5571 & 0.36 & $51.00^{35}$ \\
\hline Telephone contact time & 1000 & 0.13 & $51.00^{35}$ \\
\hline Counterweight resources booklets & 1000 & & 8.00 \\
\hline Orlistat, months & 5000 & & $31.63^{36}$ \\
\hline LELD sachets & 1000 & & $395.52^{36}$ \\
\hline \multicolumn{4}{|l|}{ Practitioner training for 1000 patients } \\
\hline Practitioners & 40 & 8 & $39.00^{35}$ \\
\hline Flights, accommodation per day & 2 & & 6000.00 \\
\hline Trainers & 4 & 8 & $59.00^{35}$ \\
\hline Teleconferences for practitioners & 40 & 4 & $39.00^{35}$ \\
\hline \multicolumn{4}{|l|}{ Total costs, $€$} \\
\hline Overall total & 861049.04 & & \\
\hline Total per patient entered & 861.05 & & \\
\hline
\end{tabular}

$17 / 38(45 \%)$ of those attending practice nurses, and $16 / 53(30 \%)$ of those attending dietitians $(P=0.15)$. Weight losses at LELD completion were similar (nurses $16.5 \mathrm{~kg}$, $\mathrm{SD}=6.2 \mathrm{~kg}$; dietitians $17.1 \mathrm{~kg}, \mathrm{SD}=5.9 \mathrm{~kg}$, $P=0.72$ ). Weight losses at 12 months achieved by nurses and dietitians were also similar $(10.5 \mathrm{~kg}, \mathrm{SD}=7.9 \mathrm{~kg}$, versus $13.7 \mathrm{~kg}$, $\mathrm{SD}=13.1 \mathrm{~kg} ; P=0.25)$

\section{Delivery and acceptability of the LELD programme}

The convenience sample for formal qualitative study was potentially biased towards patients who were more favourable towards the programme, and were protocol adherent (Appendix 1). However, there were $33 \%$ of withdrawals during the LELD, compared to $37 \%$ in unsampled patients. The qualitative analyses indicated that participants were 'very satisfied' with the rate and degree of weight loss with the LELD. Some experienced adverse physical effects such as constipation and dizziness, mostly transient, and participants appeared more concerned with social and occupational consequences. A common concern, for example, was over occasions such as family mealtimes and being confronted with food. For others, family members or friends felt uncomfortable eating around a person on the LELD.

A key aspect of the programme is re-education of participants' eating habits to prevent weight regain after programme completion. Those interviewed reported increased awareness of the importance of balancing energy intake and expenditure, and described their strategies to monitor their energy intake over the day. They were not entirely confident that weight gain could be avoided after the LELD, although weightloss maintenance for 12 months was better than anticipated from other studies. ${ }^{37}$ The practitioners interviewed were satisfied with the programme delivery, training, and support.

\section{The cost of programme delivery}

Table 3 shows an estimate of the cost, per patient entered, that would be incurred for delivery of the programme within routine NHS primary care, based on observed times and resource use in this feasibility study. The total costing for the 12-month programme, assuming delivery of the programme solely by practice nurses, was E861 per patient entered, or £2611 per documented $\geq 15 \mathrm{~kg} 12$-month-maintained loss, with $64 \%$ of the total cost incurred during the LELD (Appendix 2).

For $€ 1$ million, this programme could treat 1161 patients, to result in 12 months' maintained weight losses of $\geq 15 \mathrm{~kg}$ for 383 patients, $\geq 10 \mathrm{~kg}$ loss for 459 patients, and $\geq 5 \mathrm{~kg}$ loss for 600 patients. For comparison, the cost of laparoscopic gastric banding surgery, including appropriate preoperative assessment, 12-months' postsurgical follow-up, and band adjustments and provision to manage those who develop post-operative complications, was estimated at $€ 4988$ using 2005 prices. ${ }^{38} \mathrm{~A}$ more recent figure of $€ 8349$ was estimated by NHS Grampian. Assuming a figure of $€ 7500$, for a cost of $€ 1$ million, 133 patients could be treated with laparoscopic banding, and about 110 patients would lose $\geq 15 \mathrm{~kg} .{ }^{10}$

\section{DISCUSSION}

\section{Summary}

The results of the present study contrast with some recent UK publications that have documented the weight losses currently achieved by obese patients in routine community settings. The LightenUp trial ${ }^{39}$ demonstrated, for patients with mean BMI of $33 \mathrm{~kg} / \mathrm{m}^{2}$, mean 12-month weight losses between $1.4 \mathrm{~kg}$ (general practices) and $4.4 \mathrm{~kg}$ (commercial programmes). The Counterweight Programme target of 5-10\% weight loss was achieved and maintained for at least 2 years by 30\% of attenders, or one in six, on an ITT basis. ${ }^{27,40}$ However, with a mean $\mathrm{BMl}$ of $37 \mathrm{~kg} / \mathrm{m}^{2}$ at presentation, over one-quarter of those patients had a BMI of $\geq 40 \mathrm{~kg} / \mathrm{m}^{2}$, with a clinical need (and personal desirel for greater weight loss. The Counterweight Programme has 


\section{Funding}

This feasibility study was conducted during Scottish Government funding to develop the Counterweight Programme for primary care weight management, reference number (A1487864).

\section{Ethical approval}

The study protocol was examined by West of Scotland Research Ethics Service, which concluded that formal ethical approval was unnecessary, as no new or untested treatment was being offered, and there was no experimentation.

\section{Provenance}

Freely submitted; externally peer reviewed.

\section{Competing interests}

Michael Lean has received departmental research funding, lecture fees, and support from Cambridge Weight Plan to attend meetings to present this work. Naomi Brosnahan is an employee of Counterweight Ltd, holds shares in the company, and has received support from Cambridge Weight Plan to attend ECO 2012, relating to this work. Michael Lean, Nick Finer, John Reckless, David Haslam, Hazel Ross, and Louise McCombie are all members of the Counterweight Scientific Advisory Board. John Reckless is a non-executive director of Counterweight Ltd and holds shares in the company. Nick Finer holds shares in Counterweight Ltd. Hazel Ross and Louise McCombie are Directors of Counterweight $\mathrm{Ltd}$ and hold shares in the company. Anna Bell Higgs is an employee of Counterweight Ltd and holds shares in the company. David Haslam acts as a consultant to LighterLife. Eleanor Grieve, Mhairi Mackenzie, Philip McLoone and Billy Sloan have declared no competing interests.

\section{Acknowledgements}

We acknowledge the commitment and very substantial input of the Counterweight team, the GPs, practice nurses, and dietitians, and the patients who took part in this feasibility study. No incentives or inducements of any kind were offered to the practices or staff involved in this study. We also acknowledge the support of Dr Tony Leeds. Cambridge Weight Plan provided LELD products for this study, and contributed to the staff training related to the delivery of LELD to patients.

\section{Discuss this article}

Contribute and read comments about this article on the Discussion Forum: http://www.rcgp.org.uk/bjgp-discuss demonstrated that the level of weight loss observed in programmes such as those listed above is likely to be highly cost effective..$^{41}$ However, they do not provide the effect size required for patients with severe and complex obesity, whose sheer numbers demand a community-based solution.

\section{Strengths and limitations}

Recruitment methods may have varied between practices, to bias selection, either towards more intractable, or more compliant, patients. The present study is not a randomised controlled trial. It is difficult to recruit (particularly to a control group) and conduct such a study when a long-term outcome is desired, visible, and advertised elsewhere. A randomised controlled trial is scarcely needed to demonstrate efficacy, with results unlikely to have occurred by chance.

\section{Comparison with existing literature}

At present, VLEDs or LELDs are seldom offered within the NHS, with scepticism over their effectiveness, and non-evidence-based fears of serious hazards. ${ }^{23,24}$ Delivering composite long-term, multi-component programmes is a relatively new demand for primary care: although staff received only very limited standard training, the practices in this study may not be representative in terms of commitment or skill in weight management. The programme examined in the present paper, combining a LELD with Counterweight weight-maintenance methods, aimed to achieve and maintain for 12 months a challenging $\geq 15 \mathrm{~kg}$ weight loss for severely obese patients, in a realistic routine care setting. Such results have been achieved in research clinics: either $450 \mathrm{kcal} /$ day VLED or $810 \mathrm{kcal} /$ day LELD for 9-16 weeks produced similar results, with a 2-week structured foodreintroduction and 12-month group-therapy weight-maintenance programme resulting in $12.1 \mathrm{~kg}$ weight loss $(10.6 \%)(n=63) .42 \mathrm{~A}$ multicentre German study with $800 \mathrm{kcal} /$ day LELD, and stepwise food reintroduction, reported $35 \%$ of entering patients maintained $\geq 15 \%$ 12-month weight loss. ${ }^{43} \mathrm{~A}$ meta-analysis of VLEDs indicated that even without a long-term weight-maintenance programme, weights remained on average 3-6 kg below baseline at 12-24 months. ${ }^{15}$ Combining a VLED with anti-obesity medication generates mean weight losses of near $15 \mathrm{~kg}$ maintained $12-24$ months. ${ }^{25}$

\section{Implications for practice and research}

The present study helps inform future community-based studies around a full package of LELD, food reintroduction and long-term weight-loss maintenance. Alternatives include nutritionally complete commercial products, or cheaper homemade' liquid diets with vitamin/mineral supplements. ${ }^{30}$ The present study was not designed to compare approaches, but establishes that both can valuably be delivered in a routine primary care setting. ${ }^{44}$ Patients were initially reluctant to accept orlistat, but almost half agreed when faced with the realities of weight maintenance. The study results support published data for the efficacy of orlistat after VLED. ${ }^{24}$

Practical issues around supply and storage of the LELD were not limiting. Lack of incentives in general practice for weight management may limit implementation. The high commitment shown for the present LELD programme appeared to arise from the magnitude of weight loss achieved for patients with long-standing severe obesity, for whom previous treatments had been ineffective. During study appointments, nurses reported having also dealt with other clinical matters for which the patients would otherwise have had to make extra appointments, and practitioners indicated that many of these patients would have occupied a similar amount of staff time for other reasons if they had not been engaged on the present programme. Thus the indicative cost of the programme, $£ 861$ per patient entered or E2611 per patient losing $\geq 15 \mathrm{~kg}$, may be overestimated. These figures are highly relevant to service planners. Although major weight loss (for example, $>30 \mathrm{~kg}$ ) would be more frequent with bariatric surgery, many more patients with severe and complicated obesity would achieve the $\geq 15 \mathrm{~kg}$ loss, potentially sufficient to reverse type 2 diabetes, ${ }^{10}$ if the same resource were spent on this LELD programme. This estimate assumes that practice nurses would deliver the programme in routine practice, as their results were little different from those of dietitians. The possibility of a difference cannot be excluded. More complicated and demanding patients may require more specialist individual contact. On the other hand, dietitians would be unable to deal with other intercurrent health problems during weight management.

Questions remain about weight-loss maintenance beyond 12 months: 23\% of patients failed to engage, even to lose $\geq 5 \mathrm{~kg}$ at 12 months, a consistently frustrating finding in obesity trials. Few failed to lose any weight, indicating total failure to engage: full adherence to the LELD protocol, would have incurred a weight loss of $\geq 20 \mathrm{~kg}$ over 12 weeks. 


\section{REFERENCES}

1. NHS Information Centre. Health Survey for England - 2010: respiratory health. Leeds: The Information Centre, 2011. http://umw.ic.nhs.uk/ searchcatalogue?productid=10152\& returnid=1685 (accessed 9 Jan 2013).

2. Bromley C, Corbett J, Day J, et al. Scottish Health Survey 2010. Edinburgh: The Scottish Government, 2011. http://www.scotland.gov.uk/News/ Releases/2011/09/27102058 (accessed 12 Dec 2012).

3. Bromley C, Bradshaw P, Given L; Scottish Centre for Social Research. Scottish Health Survey 2008. Edinburgh: The Scottish Government, 2009. http://www. scotland.gov.uk/Publications/2009/09/28102003/0 laccessed 12 Dec 2012).

4. Scottish Intercollegiate Guidelines Network. Obesity in Scotland: integrating prevention with weight management. SIGN guideline no 8. Edinburgh: Scottish Intercollegiate Guidelines Network, 1996.

5. Torgerson JS, Hauptmann J, Boldrin MN, Sjostrom L. XENical in the prevention of diabetes in obese subjects (XENDOS) study: a randomised study of orlistat as an adjunct to lifestyle changes for the prevention of type 2 diabetes in obese patients. Diabetes Care 2004; 27(1): 155-161.

6. Tuomilehto J, Lindstom J, Eriksson, et al; Finnish Diabetes Prevention Study Group. Prevention of type 2 diabetes mellitus by changes in lifestyle among subjects with impaired glucose tolerance. N Engl J Med 2001; 344(18): 13431350

7. Scottish Intercollegiate Guidelines Network. Management of obesity. SIGN quideline no 115. Edinburgh: Scottish Intercollegiate Guidelines Network, 2010. http://umw.sign.ac.uk/pdf/sign115.pdf laccessed 12 Dec 2012).

8. Lean MEJ. Management of obesity and overweight. Medicine 2011; 39(1): 32-38

9. Anderson JW, Kendall CW, Jenkins DJ. Importance of weight management in type 2 diabetes: review with meta-analysis of clinical studies. J Am Coll Nutr 2003; 22(5): 331-339.

10. Dixon JB, O'Brien PE, Playfair J, et al. Adjustable gastric banding and conventional therapy for type 2 diabetes: a randomised controlled trial. JAMA 2008; 299(3): 316-323.

11. Buchwald $H$, Estok R, Fahrbach $K$, et al. Weight and type 2 diabetes after bariatric surgery: systematic review and meta-analysis. Am J Med 2009; 122(3): 248-256.

12. Lean MEJ, Powrie JK, Anderson AS, Garthwaite PH. Obesity, weight loss and prognosis in type 2 diabetes. Diab Med 1990; 7(3): 228-233.

13. Schauer PR, Kashyap SR, Wolski K, et al. Bariatric surgery versus intensive medical therapy in obese patients with diabetes. N Engl J Med 2012; 366(17): 1567-1576.

14. Lean MEJ, Finer N. ABC of obesity. Management: part II - drugs. BMJ 2006; 333(7572): 794-797.

15. Franz MJ, VanWormer JJ, Crain AL, et al. Weight-loss outcomes: a systematic review and meta-analysis of weight-loss clinical trials with a minimum 1-year follow-up. J Am Diet Assoc 2007; 107(10): 1755-1767.

16. Astrup A, Carraro R, Finer N, et al on behalf of the NN8022-1807 Investigators. Safety, tolerability and sustained weight loss over 2 years with the once-daily human GLP-1 analog, liraglutide. Int J Obesity 2012; 36(6): 843-854.

17. Lean MEJ, Astrup A, Al Hakim M, et al. Sustained weight-loss and acceptable tolerability with the GLP-1 analogue liraglutide in obese non-diabetic adults: a 2-year randomised trial. [Abstract]. Obes 2010;18(S2) S153.

18. Garrow JS. Energy balance and obesity in man. 2nd edn. Amsterdam: Elsevier, 1978.

19. Bliddal $H$, Christensen $P$, Riecke BF, et al. Osteoarthritis - a role for weight maintenance in rheumatology practice: an update. Clin Obes 2011; 1(1): 50-52.

20. Lin WY, Wu CH, Chu NF, et al. Efficacy and safety of very-low-calorie diet in Taiwanese: a multicentre randomised, controlled trial. Nutrition 2009; 25(1112): 1129-1136.

21. Christensen $H$, Bliddal BF, Riecke AR, et al. Comparison of a low-energy diet and a very low-energy diet in sedentary obese individuals: a pragmatic randomised controlled trial. Clin Obes 2011; 1(1): 31-40.

22. National Obesity Forum. Position statement on the application of Very Low Energy Diets in achieving weight loss in the management of obesity. Nottingham: National Obesity Forum, 2010. http://www.nationalobesityforum. org.uk/images/stories/_Final_version_NOF_consensus_statement_VLEDs.pdf (accessed 12 Dec 2012).

23. Lau S, Caterson ID. Meal replacement products and very low calorie diets in adult obesity. Bull R Coll Pathol 2011; 155: 172-174.

24. Richelson B, Tonstad S, Rossner S, et al. Effect of orlistat on weight regain and cardiovascular risk factors following a very-low-energy diet in abdominally obese patients: a 3-year randomised, placebo-controlled study. Diabetes Care 2007; 30(1): 27-32.

25. Mathus-Vliegen EMH for the Balance Study Group. Long-term maintenance of weight-loss with sibutramine in a GP setting following a specialist guided verylow-calorie diet: a double-blind, placebo-controlled, parallel group study. Eur J Clin Nutr 2005; 59(Suppl 1): S31-S39.

26. Apfelbaum M, Vague $\mathrm{P}$, Ziegler $\mathrm{O}$, et al. Long-term maintenance of weight-loss after a very-low-calorie diet: a randomised blinded trial of the efficacy and tolerability of sibutramine. Am J Med 1999; 106(2): 179-184.

27. The Counterweight Project Team. The implementation of the Counterweight Programme in Scotland, UK. Fam Pract 2012; 29(Suppl 1): i139-i144.

28. The Scottish Government. Scottish Index of Multiple Deprivation. http://wnw. scotland.gov.uk/Topics/Statistics/SIMD laccessed 12 Dec 2012).

29. The Counterweight Project Team. Empowering primary care to tackle the obesity epidemic: the Counterweight Programme. Eur J Clin Nutr 2005; 59(Suppl 1): S93-S101

30. Summerbell CD, Watts C, Higgins JPT, Garrow JS. Randomised controlled trial of novel, simple and well supervised weight reducing diets in outpatients. BMJ 1998; 317(7171): 1487-1489.

31. NHS Choices. The eatwell plate. London: Department of Health, 2011. http:// www.nhs.uk/Livewell/Goodfood/Pages/eatwell-plate.aspx laccessed 12 Dec 2012).

32. Schofield WN. Predicting basal metabolic rate, new standards and review of previous work. Hum Nutr Clin Nutr 1985; 39(S1): 5-41.

33. The Counterweight Project Team. A new evidence-based model for weight management in primary care: the Counterweight Programme. J Hum Nutr Diet 2004; 17(3): 191-208.

34. Chief Medical Officers of England, Scotland, Wales and Northern Ireland. Start active, stay active: a report on physical activity from the four home countries Chief Medical Officers. London: Department of Health, 2011.

35. Personal Social Services Research Unit. Source of unit costs of Health and Social Care 2011. || Community-based health care staff. http://uww.pssru.ac.uk/ archive/pdf/uc/uc2011/section2.pdf (accessed 9 Jan 2013).

36. British National Formulary. http://www.bnf.org/bnf/index.htm laccessed 12 Dec 2012).

37. Wycherley TP, Mohr P, Noakes M, et al. Self-reported facilitators of, and impediments to maintenance of healthy lifestyle behaviours following a supervised research-based lifestyle intervention programme in patients with type 2 diabetes. Diabet Med 2012; 29(5): 632-639.

38. Ackroyd R, Mouiel J, Chevallier JM, Daoud F. Cost-effectiveness and budget impact of obesity surgery in patients with type-2 diabetes in three European countries. Obes Surg 2006; 16(11): 1488-1503.

39. Jolly K, Lewis A, Beach J, et al. Comparison of range of commercial or primary care led weight reduction programmes with minimal intervention control for weight-loss in obesity: Lighten Up randomised controlled trial. BMJ 2011; 343: d6500.

40. The Counterweight Project Team. Evaluation of the Counterweight Programme for obesity management in primary care: a starting point for continuous improvement. Br J Gen Pract 2008; 58(553): 548-554.

41. The Counterweight Project Team. Long-term cost effectiveness of weight management in primary care. Int J Clin Pract 2010; 64(6): 775-783.

42. Johansson $\mathrm{K}$, Hemmingsson $\mathrm{E}$, Harlid R, et al. Longer term effects of very low energy diet on obstructive sleep apnoea in cohort derived from randomised controlled trial: prospective observational follow-up study. BMJ 2011; 342: d3017.

43. Bischoff SC, Damms-Machado A, Betz C, et al. Multicenter evaluation of an interdisciplinary 52-week weight-loss program for obesity with regard to body weight, comorbidities and quality of life - a prospective study. Int J Obes 2012; 36(4): 614-624

44. Lean MEJ, Tigbe WW, Briggs, et al. A patient-centred approach to estimate total annual healthcare costs by body mass index in the UK Counterweight programme. Obes Rev 2012. [Epub ahead of print]. http://uww.nature.com/ doifinder/10.1038/ijo.2012.186 (accessed 9 Jan 2013). 
Appendix 1. Weight outcomes among the qualitative sample compared to unsampled patients

\begin{tabular}{lcc} 
& Qualitative sample & Other patients \\
\hline$n$ & 15 & 76 \\
\hline Initial weight, kg (SD) & $131.6(28.4)$ & $131(24.8)$ \\
\hline$\%$ withdrawing during LELD $(n)$ & $33(5)$ & $37(28)$ \\
\hline Mean weight loss after LELD, kg (SD) & $18.9(5.1)$ & $16.4(6.1)$ \\
\hline$\%$ losing >15 kg after LELD $(n)$ & $60(9)$ & $38(29)$ \\
\hline$\%$ providing 12-month weight $(n)$ & $87(13)$ & $72(55)$ \\
\hline Mean weight loss at 12 months, kg (SD) & $13.2(8.3)$ & $30(23)$ \\
\hline$\%$ with $>15 \mathrm{~kg}$ weight loss at 12 months $(n)$ & $47(7)$ &
\end{tabular}




\section{Appendix 2. Time and resources used during each stage in the LELD and weight-loss maintenance programme}

\begin{tabular}{|c|c|c|c|c|c|c|}
\hline & LELD & $\begin{array}{l}\text { Food } \\
\text { reintroduction }\end{array}$ & $\begin{array}{c}\text { Weight } \\
\text { maintenance }\end{array}$ & $\begin{array}{c}\text { Across } \\
\text { programme }\end{array}$ & Total & Note \\
\hline Number of patients starting & 91 & 54 & 52 & & 91 & \\
\hline Number of patients completing & 58 & 48 & 30 & & & 1 \\
\hline \multicolumn{7}{|l|}{ Staff contacts } \\
\hline GP time & $€ 1692.60$ & & & & $£ 1692.60$ & 2 \\
\hline Medical queries & & & & $£ 401.00$ & $€ 401.00$ & 3 \\
\hline Practice nurse visits & $348(n=38)$ & & 139 & & & \\
\hline Practice nurse time & $€ 5279.35$ & & $€ 1805.40$ & & $€ 7084.75$ & 4 \\
\hline Dietitian visits & $475(n=53)$ & & 289 & & & \\
\hline Dietitian time & €17 108.00 & & $£ 10492.30$ & & $€ 27600.30$ & 5 \\
\hline All visits & 823 & & 428 & & & \\
\hline All contact time & $17491(n=91)$ & & 9041 & & 26532 & \\
\hline \multicolumn{7}{|l|}{ Telephone contacts } \\
\hline \multicolumn{7}{|l|}{ Number of calls } \\
\hline Time, minutes & $£ 867.38$ & & $€ 565.63$ & & $€ 1433.02$ & 6 \\
\hline Counterweight resources & $€ 455.00$ & & & & $€ 455.00$ & 7 \\
\hline Orlistat, days & & & $€ 8980.66$ & & $£ 8980.66$ & 8 \\
\hline LELD sachets & €40 140.00 & $€ 8352.00$ & & & $€ 48492.00$ & 9 \\
\hline \multirow[t]{3}{*}{ Practitioner training by Counterweight specialists } & $€ 5648.00$ & & & & & 10 \\
\hline & $€ 4719.00$ & & & & $€ 10367.00$ & 11 \\
\hline & $€ 944.00$ & & & & E944.00 & 12 \\
\hline Practitioner teleconferences & & & & $€ 2748.00$ & $€ 2748.00$ & 13 \\
\hline Counterweight specialist & & & & $€ 8281.00$ & $€ 8281.00$ & 14 \\
\hline Central Counterweight data collection and analyses & $€ 521.08$ & & & & $€ 521.08$ & 15 \\
\hline Total & $€ 77374.42$ & $€ 8352.00$ & €21843.99 & $£ 11430.00$ & $€ 119000.41$ & \\
\hline \multicolumn{7}{|c|}{ 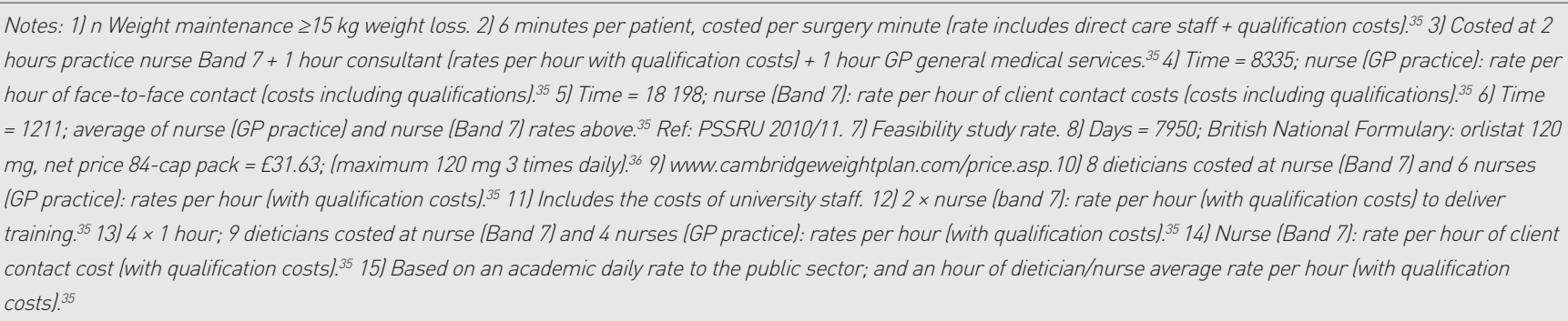 } \\
\hline
\end{tabular}

